\title{
Removal of Dissolved Organic Matter by Magnetic Ion Exchange Resin
}

\author{
Treavor H. Boyer ${ }^{1}$ (D)
}

Published online: 11 August 2015

(C) Springer International Publishing AG 2015

\begin{abstract}
This article provides a state-of-the-art review on the uses of magnetic ion exchange (MIEX) resin in drinking water and wastewater treatment, with emphasis on removal of dissolved organic matter (DOM) from drinking water and wastewater, regeneration efficiency, removal of inorganic and synthetic organic chemicals, comparison with other anion exchange resins, and integration with other physical-chemical processes. Through laboratory jar tests, pilot plant tests, and full-scale installations for a variety of drinking water sources, MIEX resin can achieve 30-80 \% removal of dissolved organic carbon (DOC), which is often higher than alum or ferric coagulation. In addition, MIEX resin has been shown to remove hydrophilic, transphilic, and hydrophobic fractions of DOM and a wide range of molecular weight fractions of DOM. As a result, MIEX pretreatment results in substantial reductions in the formation of trihalomethanes and haloacetic acids upon chlorination. MIEX resin can achieve bromide removal in the range of 10-50\%, with higher bromide removal in waters with low DOC, low alkalinity, and low sulfate. However, there are commercially available anion exchange resins that are more selective for bromide than MIEX resin. MIEX resin has been investigated in combination with coagulation, activated carbon adsorption, membrane separation, lime softening, and ozonation. MIEX pretreatment has been shown to reduce downstream chemical requirements and
\end{abstract}

This article is part of the Topical Collection on Water Pollution

Treavor H. Boyer

thboyer@ufl.edu

1 Department of Environmental Engineering Sciences, Engineering School of Sustainable Infrastructure \& Environment (ESSIE), University of Florida, P.O. Box 116450, Gainesville, FL 32611-6450, USA improve the operation of downstream processes. This is most evident for coagulation and ozonation where the coagulant dose can be reduced by $50-75 \%$ and the ozone concentration can be increased by $40-65 \%$. In general, MIEX pretreatment shows minor reductions in membrane fouling. Future research should continue to investigate the integration of MIEX treatment with other processes.

Keywords Bromide $\cdot$ Coagulation $\cdot$ Disinfection byproducts (DBPs) - Dissolved organic carbon (DOC) · Magnetic ion exchange (MIEX) $\cdot$ Membrane fouling

\section{Introduction}

The terms dissolved organic matter (DOM), natural organic matter, and humic substances are often used interchangeably to describe the mixture of complex organic compounds present in water. The term DOM is used in this article to encompass both natural and anthropogenic sources of aquatic organic matter. Characterization and removal of DOM is of interest to many engineers and scientists because removal of DOM is a critical step during drinking water treatment, most prominently because DOM is the main precursor material to disinfection byproducts (DBPs). Also of concern during drinking water treatment is that DOM imparts color to water, exerts chemical demand, fouls membranes, and acts as a substrate for microbiological growth in water distribution systems. To add to these concerns, there is research showing increasing DOM content in surface waters and drinking water supplies in many parts of the world due to changes in climate and land use [1, 2]. Another recent trend pertaining to DOM is interest in removing DOM as part of domestic and industrial wastewater treatment for water reuse applications. 
Given the widespread importance of DOM removal during drinking water and wastewater treatment, numerous physicalchemical removal or destruction processes have been investigated including coagulation/flocculation [3], precipitation, adsorption, membrane separation [4], and chemical oxidation [5]. Coagulation/flocculation and activated carbon adsorption are two of the most widely studied and implemented processes for DOM removal. Anion exchange and membrane technology have emerged as alternative processes to coagulation/ flocculation and activated carbon adsorption for DOM removal. In particular, anion exchange is of interest as a DOM removal technology because it can achieve high levels of DOM removal, remove wide range of DOM types, can be applied in different reactor configurations, and can be operated continuously or intermittently. Among various anion exchange resins and processes, magnetic ion exchange (MIEX) resin has been the main focus of research and practice on DOM removal by anion exchange since the early 2000 s $[6-10,11 \bullet \bullet, 12 \bullet]$.

Although there are many previous review articles on physical-chemical processes for DOM removal such as coagulation and membrane technology, there are no previous review articles on DOM removal by anion exchange or MIEX. This represents a critical gap in the literature since there is no synthesis of the current knowledge or insights on the needs for future research. Accordingly, the goal of this article was to provide a state-of-the-art review on the uses of MIEX resin in drinking water and wastewater treatment. The specific objectives of this review article were to evaluate MIEX treatment considering (i) removal of DOM from drinking water and wastewater sources, (ii) removal of inorganic and synthetic organic chemicals, (iii) comparison with other anion exchange resins, (iv) integration with other physical-chemical processes, and (v) needs for future research. Magnetic ion exchange was selected as the scope for this review article because the majority of research on DOM removal by anion exchange has focused on MIEX resin. As such, this review article was able to draw on a rich body of literature in which a wide range of water types, contaminants, and test conditions have been investigated for a single type of anion exchange resin.

\section{Background on MIEX}

MIEX is a commercially available anion exchange resin and an ion exchange process used in drinking water treatment. MIEX resin and its process were developed by the Australian company and research organizations Orica, Commonwealth Scientific Industrial Research Organization, and South Australian Water Corporation. The patents on MIEX resin and the MIEX process were issued in 2001 and 2003, respectively $[13 \bullet \bullet, 14 \bullet \cdot]$. The article by Slunjski et al. gives a useful overview and timeline on the development and commercialization of MIEX [15]. The first full-scale installations of MIEX were at the Mt. Pleasant Water Treatment Plant (2.5 ML/day, 0.66 million gal/day) in South Australia and Wanneroo Groundwater Treatment Plant (112.5 ML/day, 29.7 million gal/day) in Western Australia [15]. In this paper, MIEX resin is used to refer to the specific anion exchange resin, while MIEX treatment is used to describe the continuous flow, completely mixed ion exchange process that uses MIEX resin. Although the main focus of this review article is on a single commercial product/process, the interest in MIEX treatment in the drinking water and wastewater industry has motivated new research and development on alternative magnetic ion exchange resins and novel ion exchange processes. Thus, the knowledge gained on MIEX treatment is generally transferable to DOM removal by magnetic and non-magnetic anion exchange resins in various process configurations for a wide range of water types.

MIEX resin is a magnetically enhanced anion exchange resin that consists of a macroporous polyacrylic bead dispersed with magnetic iron oxide particles. The resin is functionalized with quaternary ammonium (i.e., trimethylamine functional groups) and typically uses chloride as the mobile counterion. The particle size of MIEX resin is approximately $200 \mu \mathrm{m}[16,17 \cdot, 18]$, which is $2-5$ times smaller than conventional anion exchange resins. Because of the small particle size and magnetic component, MIEX resin is used in a completely mixed flow reactor (CMFR) with resin recycle and partial resin regeneration (i.e., the MIEX process or MIEX treatment). At the time the MIEX process was developed, and hence patented [13••], it was a new process configuration for ion exchange resin that had important advantages over the conventional approach of using ion exchange resin in fixed bed reactor as a final polishing step. For instance, MIEX treatment is typically used at the beginning of a treatment train because turbidity does not adversely impact the process. This allows for high reductions in DOC, which decreases subsequent chemical requirements (e.g., coagulants), and improves the performance of downstream processes (e.g., membranes).

An interesting side note on MIEX resin is the limited extent by which the role of magnetic iron oxide on resin behavior has been investigated. In the patent for MIEX resin [14••], it describes the preparation process for magnetic polymer beads using $\gamma-\mathrm{Fe}_{2} \mathrm{O}_{3}$ (maghemite). It mentions in the patent that one of the advantages of magnetic resin is the magnetic attraction or separation of the beads; however, no data are provided to support this. In the patent, it also mentions that adding solid particles, such as maghemite, to polymer beads will increase the density and weight of the beads. In the patent for the MIEX process [13••], it describes key steps in the process such agglomeration of magnetic particles and the rapid settling of dense magnetic polymer beads; however, no data are provided to illustrate these steps. In the peer-reviewed literature, Jha et al. were the first to investigate the magnetic properties of MIEX resin and use a magnetic reactor [16]. The authors 
reported that MIEX resin had a saturation magnetization of $17 \mathrm{emu} / \mathrm{g}$ and behaved "paramagnetically with negligible remnant magnetization in the absence of a magnetic field" [16]. These results do not agree with magnetic polymer beads containing magnetic particles such as maghemite [14••], which is ferrimagnetic [19]. Indarawis and Boyer investigated the magnetic properties of magnetically enhanced cation exchange resin from Orica Watercare, which was assumed to be produced in a similar manner as MIEX resin [14.•], and suggested that cationic MIEX resin contained magnetite [20], which is more consistent with the patented process for MIEX resin. In summary, the magnetic characteristics and behavior of MIEX resin remains an open research question.

\section{DOM Removal from Drinking Waters Sources}

MIEX resin was created as an alternative process to coagulation for removal of dissolved organic carbon (DOC) and subsequent reduction in DBP formation upon chlorination. The majority of data on DOC removal by MIEX resin is from jar tests (similar to coagulation jar tests) or batch tests (similar to activated carbon adsorption tests). There is also data on DOC removal by MIEX resin from pilot plant tests and full-scale installations [7, 21, 22]. Researchers have also developed alternative testing procedures, such as multiple-loading jar tests and fluidized bed column tests, to investigate other process configurations for MIEX resin. MIEX tests have been conducted using drinking water sources from all over the world, e.g., Australia, China, Japan, Poland, Turkey, UK, and USA $[6,8,9,23-25]$. Most data for MIEX resin is from $\mathrm{NaCl}$ regeneration with limited data from $\mathrm{NaHCO}_{3}$ regeneration $[18,21,26-28]$.

\section{Jar Tests}

Jar tests have been used to compare MIEX resin with aluminum sulfate (alum) and ferric chloride (ferric) coagulation in terms of removal of DOC and UV absorbance at $254 \mathrm{~nm}$ (UVA254) and reduction in trihalomethane (THM) and haloacetic acid (HAA) formation for a wide range of drinking water sources. Jar tests typically consist of MIEX resin doses of $1-10 \mathrm{~mL} / \mathrm{L}$ and mixing times of 5-60 min. Removal of DOC and reduction in UVA254 by MIEX resin is generally greater than or equal to removal by alum or ferric coagulation. For example, Drikas et al. showed DOC removals of 64 and $74 \%$ by MIEX resin for two different raw waters with corresponding DOC removals of $22-28$ and $41-53 \%$ by alum coagulation [29]. Reduction in UVA254 followed a similar trend as DOC removal for MIEX resin and alum coagulation [29]. Many subsequent researchers have shown similar results of high-DOC and UVA254 removal by MIEX resin [18, 23, 30-37]. For example, Boyer and Singer showed greater removals of DOC and UVA254 by MIEX resin than alum coagulation across four different raw waters with the extent of removal increasing as the specific UVA254 (SUVA254) of the raw water increased from 2.0 to $3.8 \mathrm{~L} / \mathrm{mg} \cdot \mathrm{m}$ [31]. For low SUVA254 water $(2 \mathrm{~L} / \mathrm{mg} \cdot \mathrm{m})$, MIEX resin preferentially reduced the UVA254 fraction of DOM with treated water SUVA254 of $1.15 \mathrm{~L} / \mathrm{mg} \cdot \mathrm{m}$ and $55 \%$ DOC removal [38]. For some raw waters, however, coagulation shows greater removal of DOC and UVA254 than MIEX resin. For example, Fearing et al. compared ferric coagulation with MIEX resin and showed higher removal of DOC and UVA254 by ferric coagulation than MIEX resin and subsequent greater reductions in THM formation for ferric than MIEX-treated samples [39]. The raw water used in Fearing et al. had a high SUVA254 (4.5-5.1 L/mg.m) [39], which makes the DOC amenable to coagulation and may explain the better performance of coagulation over MIEX resin.

MIEX resin has also been tested for removal of DOC from nanofiltration (NF) and reverse osmosis (RO) concentrate derived from high-DOC groundwater. Whereas MIEX resin doses of $0.5-5 \mathrm{~mL} / \mathrm{L}$ are typically used for drinking water sources [6, 31, 39], NF and RO concentrate require MIEX resin doses on the order of 10-20 mL/L. For example, DOC removal from various NF/RO concentrates was $51-87 \%$ at MIEX resin dose of $20 \mathrm{~mL} / \mathrm{L}$ [40].

The majority of data for MIEX resin is based on chloride as the mobile counterion and $\mathrm{NaCl}$ as the regeneration agent. However, disposal of $\mathrm{NaCl}$ waste brine to the sewer, receiving waters, or landscape can be problematic in terms of excess sodium and chloride. As a result, $\mathrm{NaHCO}_{3}$ has been investigated as an alternative to $\mathrm{NaCl}$ regeneration. MIEX resin using either chloride or bicarbonate as the mobile counterion showed the same order of removal with UVA254 $>$ DOC $>$ sulfate $>$ nitrate and the performance of the resin remained constant over three regeneration cycles using $\mathrm{NaCl}$ or $\mathrm{NaHCO}_{3}$ regeneration [26]. In another study, $\mathrm{NaHCO}_{3}$ showed slightly lower regeneration efficiency than $\mathrm{NaCl}$ over 21 regeneration cycle with $69 \pm 8 \%$ DOC removal by bicarbonate-form MIEX resin and $74 \pm 6 \%$ DOC removal by chloride-form resin [18].

MIEX resin typically removes a wider range of DOC in terms of hydrophobicity and molecular weight than coagulation and activated carbon adsorption, whereas coagulation targets the hydrophobic, high molecular weight fractions of DOC $[29,41]$ and powdered activated carbon (PAC) adsorption targets the hydrophilic, low molecular weight fractions of DOC $[42,43 \bullet]$. For example, Boyer and Singer showed similar removal of hydrophobic acid, transphilic acid, and hydrophilic acid fractions of DOC by MIEX resin [31], and Humbert et al. showed that MIEX resin removed both low and high apparent molecular weight fractions of DOM [33]. Others have shown that MIEX resin preferentially removes transphilic and hydrophilic fractions of DOM relative to PAC adsorption [42], and MIEX resin removes a wider range 
of apparent molecular weight fractions of DOM than PAC or alum coagulation [43•].

Chlorination of water samples following MIEX treatment typically show high reductions in THMs and HAAs [29] and greater reductions in THMs than HAAs than coagulation [29, 37]. For example, Singer and Bilyk showed THM reductions of $71-84 \%$ by MIEX treatment of several different drinking water sources and similar reductions in HAAs as THMs [6]. In addition, chlorination of MIEX-treated samples showed lower HAA formation than alum coagulated samples [6]. Because MIEX resin achieved greater removal of transphilic and hydrophilic fractions of DOM than PAC, upon chlorination the MIEX-treated samples resulted in lower formation of THMs and HAAs than PAC [42].

\section{Pilot Plant Tests and Full-Scale Installations}

MIEX pilot plant tests and full-scale installations have confirmed many of the results from MIEX jar tests. For instance, a MIEX pilot plant study showed increasing DOC removal with increasing effective resin dose [21], which is a concept that was created to compare MIEX jar test results with the continuous flow, completely mixed MIEX process. For example, a MIEX pilot plant operating with $20 \mathrm{~mL} / \mathrm{L}$ MIEX resin and $10 \%$ regeneration ratio corresponds to an effective resin dose of $2 \mathrm{~mL} / \mathrm{L}$ [21], which should perform similar to a jar test dose of $2 \mathrm{~mL} / \mathrm{L}$ MIEX resin. The MIEX pilot plant study by Boyer and Singer was the first to show that increasing sulfate concentration in the raw water resulted in lower DOC removal by MIEX resin and showed that the DOC recovered during regeneration was approximately equal to the DOC removed during treatment [21]. Other MIEX pilot plant tests have evaluated the effect of process operating conditions (resin concentration, contact time, and regeneration frequency) and raw water quality on DOC removal by MIEX resin [44, 45]. Pilot plant tests have also been used to evaluate the sequence of MIEX treatment with other processes, e.g., MIEX prior to granular activated carbon (GAC) biofilters [46], which are also referred to in the literature as biologically active carbon (BAC) filters.

The novelty of the MIEX process combined with the greater time commitments of pilot plant tests over jar tests motivated the development of a MIEX process model. The model was developed to describe DOC removal by MIEX resin in a CMFR with resin recycle and partial resin regeneration [17]. The novel aspect of the model was tracking the evolving age distribution of MIEX resin particles in the reactor for different regeneration frequencies. The model results showed good agreement with previous pilot plant studies [17]. The model developed to describe the MIEX process was extended to also describe a fluidized bed ion exchange process, where both the MIEX process (i.e., CMFR) and fluidized bed reactor could be summarized in terms of the effective resin dose and solids residence time [47].

Researchers have evaluated the world's first large-scale MIEX installation at the Wanneroo Groundwater Treatment Plant, Perth, Australia, to compare MIEX, MIEX followed by alum coagulation (hereafter MIEX/coagulation), and enhanced alum coagulation in terms of removal of DOC and its apparent molecular weight fractions from size exclusion chromatography $[7,22]$. The general order of decreasing DOC removal was MIEX/coagulation>enhanced coagulation $>$ MIEX, with enhanced coagulation being the most effective for removal of high apparent molecular weight fractions of DOM and MIEX resin removing medium range apparent molecular weight fractions of DOM [7]. These trends were observed to vary with season due to changes in the concentration and character of DOM [22]. Singer et al. synthesized data from MIEX jar tests, pilot plant tests, and full-scale installations and showed that DOC removal increased as SUVA254 increased at a constant MIEX resin dose where the resin dose included the jar test dose and the effective resin dose from pilot plant tests and full-scale installations [48].

\section{Multiple-Loading Jar Tests}

Researchers have developed alternative laboratory testing procedures to better mimic the continuous flow, completely mixed MIEX process. In particular, the multiple-loading jar test procedure uses the same batch of resin to treat multiple batches of raw water. By following this procedure, DOC removal by MIEX resin can be expressed as the number of resin bed volumes treated, which is more representative of the fullscale MIEX process. For example, Kitis et al. showed 29$39 \%$ DOC removal after 1200 bed volumes of MIEX treatment [23]. Mergen et al. applied the multiple-loading procedure to three different water types and showed that MIEX resin exhibited consistent removal of hydrophilic DOC, whereas the removal of hydrophobic DOC steadily decreased with increasing number of bed volumes treated [8]. The authors concluded that the multiple-loading approach gave a more realistic indication of DOC removal by MIEX resin. MIEX treatment following the multiple-loading procedure was also applied to model organic compounds and showed the general trend of higher removal of hydrophobic and hydrophilic anionic species than hydrophilic neutral species [49]. The multiple-loading jar test procedure has been used to evaluate the effect of temperature in which there was not a significant difference in DOC removal by MIEX resin at 1 and $20{ }^{\circ} \mathrm{C}$ [50]. Multiple-loading MIEX treatment (600 bed volumes) of surface water and effluent impacted water resulted in 39-87\% reductions in UVA254, DOC, THM4, and HAA9, 10-33\% reduction in halonitromethane formation, and increase in NDMA formation in effluent impacted samples $[10,51 \bullet \cdot]$. These are the first results showing reductions in 
THM and HAA formation using the multiple-loading approach and are in agreement with results from MIEX jar tests.

\section{DOM Removal from Wastewater}

Given the effectiveness of using MIEX resin to remove DOC from raw drinking water, MIEX resin has been applied to biologically treated wastewater effluent and other waste streams. For example, MIEX resin showed similar removal of hydrophobic, transphilic, and hydrophilic fractions of DOC from biologically treated wastewater effluent and maintained a consistent level of DOC removal over 10 regeneration cycles [52]. In follow-up work, MIEX, MIEX/coagulation, coagulation, and PAC were investigated as pretreatments to reduce fouling on microfiltration (MF) membranes [27, 53, 54]; MIEX pretreatment showed only minor reductions in membrane fouling. In a different study, MIEX resin was used to remove DOC from tertiary treated wastewater effluent, and the results showed almost complete removal of the organic acid fraction of DOM and substantial decrease in fouling on MF and ultrafiltration (UF) membranes [55]. MIEX resin was compared with polyaluminum chloride (PACl) coagulation of secondary wastewater effluent, and MIEX resin showed preferential removal of low molecular weight organic acids, whereas $\mathrm{PACl}$ coagulation showed preferential removal of high molecular weight biopolymers [56]. Both MIEX and $\mathrm{PACl}$ showed minor reductions in MF fouling. In another study, MIEX resin was used in a fluidized bed reactor to treat synthetic wastewater effluent and showed $60 \%$ DOC removal up to 172 bed volumes [57], which is comparable to DOC removal as drinking water treatment but 10 times lower than the throughput volume $[8,23]$. MIEX resin has also been tested to treat secondary wastewater effluent in preparation for aquifer recharge. MIEX resin showed statistically significant reductions in DOC, UVA254, color, total nitrogen, nitrate, total phosphate, and sulfate in the secondary effluent [58]. In a related study, treatment of secondary wastewater effluent before soil aquifer treatment showed DOC removal trend of $\mathrm{NF}>\mathrm{MIEX}>$ ozone $\approx \mathrm{UF}$ [59]; however, ozonation made the wastewater more amenable to soil aquifer treatment than MIEX because ozone increased the biodegradability of DOC.

Other waste streams that have treated using MIEX resin include greywater [60] and landfill leachate [61-63]. For example, the removal preference of MIEX resin for various components of landfill leachate was color $>$ UVA254 $>$ DOC $\approx$ chemical oxygen demand (COD) $>$ biochemical oxygen demand $(\mathrm{BOD}) \approx$ total nitrogen $(\mathrm{TN})$ where MIEX resin showed minimal removal of BOD and TN [61].

\section{Regeneration Efficiency}

Given that MIEX is an anion exchange process, it is surprising that there are considerably fewer published studies on regeneration and desorption than contaminant removal, especially for DOM. Most of the studies that evaluate regeneration of MIEX resin track the removal efficiency of DOC over several regeneration cycles $[27,57,61]$. These studies show that MIEX resin can be effectively regenerated using $\mathrm{NaCl}$ as indicated by consistent level of DOC removal over multiple regeneration cycles. As an alternative to $\mathrm{NaCl}, \mathrm{NaHCO}_{3}$ has also been evaluated for regeneration of MIEX resin and typically shows lower regeneration efficiency than $\mathrm{NaCl}$ as measured by DOC removal [18, 26, 64]. Other approaches that have been used to evaluate regeneration and desorption include mass balance and stoichiometry calculations. For example, at the process level, mass balance calculations made as part of a MIEX pilot plant study showed that DOC removed during treatment was equal to DOC recovered during regeneration [21]. At the mechanism scale, DOC removal by MIEX resin was shown to be equal to chloride release on an equivalent concentration basis, thus confirming the ion exchange stoichiometry $[65,66]$. Overall, there is consistent supporting data in the literature that MIEX resin is effectively regenerated using $\mathrm{NaCl}$ and, to a lesser extent $\mathrm{NaHCO}_{3}$, and can be used for multiple treatment cycles.

\section{Removal of Inorganic and Synthetic Organic Chemicals}

\section{Inorganic Chemicals}

Although the focus of this review is on DOM removal by MIEX resin, it is informative to also review the removal of inorganic and synthetic organic chemicals by MIEX resin due to considerations such as co-removal of DOM and other contaminants and the impact of other contaminants on DOM removal. Co-removal of bromide and DOC using MIEX resin has been investigated by many researchers due to the opportunity to remove both organic and inorganic precursors leading to halogenated organic DBPs. However, the effectiveness of MIEX resin to remove both bromide and DOC has shown mixed results. Depending on the water source and MIEX resin dose, bromide removal by MIEX resin can vary from $>90$ to $<10 \%[6,25,31-33,41]$. However, an explanation for the variable removal of bromide by MIEX resin is often lacking from a discussion of the results. Johnson and Singer systematically investigated bromide removal by MIEX resin by spiking raw natural water with bromide and showed increasing bromide removal with increasing MIEX resin dose and decreasing bromide removal with increasing alkalinity [32]. The adverse impact of alkalinity on bromide removal suggests 
competition between bicarbonate and bromide for exchange sites on the resin as bicarbonate is present at several orders of magnitude higher concentration than bromide. Others have also reported higher bromide removal by MIEX resin in low alkalinity water than higher alkalinity water [31, 33, 67••], with the order of increasing competition with bromide being chloride $<$ bicarbonate/carbonate $<$ sulfate [68]. In contrast to the results for bromide, increasing alkalinity did not affect iodide removal by MIEX resin [67••]. MIEX resin showed similar removal of bromide using either chloride or bicarbonate as the mobile counterion [18]. In addition to competition among bromide, DOC, and other inorganic anions, the polymer composition of MIEX resin makes it less selective for removal of bromide. Polystyrene anion exchange resins have been shown to remove greater amounts of bromide than polyacrylic MIEX resin, whereas MIEX resin removed greater amount of DOC than polystyrene resin [69].

MIEX resin has also been investigated for removal of other inorganic anions including sulfate [18, 33], nitrate [26, 33], phosphate [70, 71], chromium(VI) [16], arsenic(V) [16], iodide $[67 \bullet \cdot]$, and perchlorate $[72,73]$, some of which may compete with DOM for exchange sites on MIEX resin. The extent of removal of inorganic chemicals depends on the initial chemical concentration, MIEX resin dose, and competing species. For example, at high initial inorganic chemical concentration removal by MIEX resin can be limited by ion exchange capacity, especially for water or wastewater with high sulfate concentration [40]. The selectivity of MIEX resin for DOM and inorganic anions is sulfate $>$ DOM $>$ bromide $\approx$ nitrate $>$ bicarbonate $\approx$ chloride $[65,66]$, where some fractions of DOM have a selectivity comparable to sulfate, whereas other fractions of DOM are much less preferred than sulfate. The placement of phosphate, iodide, and perchlorate in the selectivity sequence for MIEX resin is difficult to estimate due to the different experimental conditions. A reasonable estimate based on the previous literature is sulfate $>$ perchlorate $\approx$ DOM $>$ iodide $>$ bromide $\approx$ nitrate $>$ phosphate $>$ bicarbonate $\approx$ chloride.

\section{Synthetic Organic Chemicals}

MIEX resin has been investigated for removing a variety of synthetic organic chemicals including pharmaceuticals and pesticides. The functional groups present in synthetic organic chemicals that make these chemicals amenable to anion exchange are the same functional groups present in DOM that allow for anion exchange [65, 74]. For anionic chemicals, such as bentazone and 2,4-dichlorophenoxyacetic acid [74-76], MIEX resin shows high removal up to $99 \%$, whereas for non-ionic chemicals, such as atrazine and isoproturon, MIEX resin shows negligible removal [33]. MIEX resin removed approximately $40 \%$ of estrone at $\mathrm{pH} 8$ (neutral molecule) and removal increased to approximately $70 \%$ at $\mathrm{pH} 12$ where estrone is negatively charged [77]. MIEX resin showed $0-48 \%$ removal of 15 commonly detected pharmaceuticals and personal care products with higher removal observed for negatively charged species [78]. These results follow directly from the mechanism of ion exchange as shown by Liu et al. for bentazone [75] and discussed in the next section for DOM. In contrast to the previous results, removal of tetrabromobisphenol A by MIEX resin decreased as $\mathrm{pH}$ increased [79], which is not expected since tetrabromobisphenol $\mathrm{A}$ is neutral at $\mathrm{pH}<7.5$ and negatively charged at $\mathrm{pH}>7.5$. The contradictory results for tetrabromobisphenol A could be due to low solubility and analytical error at acidic $\mathrm{pH}[80]$.

\section{Comparison with Other Anion Exchange Resins}

MIEX resin and conventional anion exchange resins behave by the same mechanism of removal, which is stoichiometric exchange between the chloride counterion and carboxylic acid functional groups of DOM [65]. As a result, when the dose of MIEX resin and conventional anion exchange resins are normalized to the same ion exchange capacity, MIEX resin and non-magnetic polyacrylic anion exchange resins show similar levels of DOC removal and greater DOC removal than polystyrene resin [65]. It is important to note that the previous results apply to mixing times on the order of hours to days. At short mixing times on the order of minutes, MIEX resin shows a faster rate of DOC removal than conventional anion exchange resins $[33,37]$. MIEX resin was compared with six other commercially available strong-base anion exchange resins, which are marketed for organics removal, and showed faster and greater reductions in UVA254 from 5 to $30 \mathrm{~min}$ [12•]. As mixing times approach hours, MIEX resin showed similar DOC removal as other polyacrylic resins and some polystyrene resins [25]. This was especially true when MIEX resin was compared with PFA444 resin (strong-base, gel, polystyrene) using a two-stage countercurrent configuration where both resins showed similar removals of DOC [12•]. MIEX resin showed the lowest removal of bromide among a variety of polyacrylic and polystyrene anion exchange resins [25]. However, when comparing MIEX resin to conventional anion exchange resins for removal of inorganic anions, it is important to consider that MIEX resin has a lower strong-base anion exchange capacity, e.g., $0.52 \mathrm{meq} / \mathrm{mL}$ MIEX resin and $1.4 \mathrm{meq} / \mathrm{mL}$ IRA400 resin. Multiple-loading jar tests were used to compare MIEX resin and DOWEX 11 resin (strongbase, polystyrene) with respect to DOC and sulfate removal in low- and high-sulfate waters. DOC removal by both resins was similar in each water with higher DOC removal in the low sulfate water [81]. The most notable difference between MIEX resin and DOWEX 11 resin was the greater sulfate removal by DOWEX 11 resin [81]. High removal of sulfate is usually not a water treatment objective, so the higher 
loading of sulfate on DOWEX 11 resin could lead to loss of ion exchange capacity over multiple regeneration cycles. MIEX resin was compared with two strong-base, polystyrene resins with biquaternary ammonium functional groups (i.e., triethylamine and trihexylamine). All three resins showed similar removal of perchlorate in the absence of competing anions; however, perchlorate removal by MIEX resin in the presence of sulfate was reduced from 87 to $31-49 \%$, whereas the presence of sulfate did not affect perchlorate removal by the other biquaternary ammonium resins [73]. This is because larger spaced quaternary ammonium functional groups, such as triethyl- and trihexylamine, are more selective for monovalent anions over divalent anions than closely spaced trimethylamine functional groups in MIEX resin [82].

In addition to commercially available MIEX resin, other magnetically enhanced ion exchange resins and adsorbents have been developed for a variety of applications [83]. For example, quaternized magnetic polyacrylic microspheres (referred to as NDMP resin) were synthesized and compared with MIEX resin for removal of reactive dyes. NDMP resin had a higher strong-base anion exchange capacity than MIEX resin, which resulted in greater adsorption of reactive dyes by NDMP resin than MIEX resin [84]. The NDMP resin was effectively regenerated using $10 \% \mathrm{NaCl}$ and showed consistent level of dye removal over 20 regeneration cycles [84]. Other research has shown that electrolysis of NDMP-treated water can be used to generate chlorine (from the released chloride counterion) and disinfect the water [85]. A different magnetic anion exchange resin (NDM-1) was synthesized in which the functional group was triethylamine instead of trimethylamine on MIEX resin and as a result, the NDM-1 resin showed greater adsorption of nitrate than MIEX resin in the presence of sulfate [86], similar to the results discussed for perchlorate. Another magnetic resin, magnetic poly(glycidyl methacrylate), was synthesized and compared with MIEX resin for removal of DOM and carbamazepine [87].

\section{Integration with Physical-Chemical Processes}

\section{Coagulation}

One of the main advantages of MIEX resin is as a pretreatment to coagulation, whereby the coagulant dose can be reduced by $50-75 \%[6,88,89]$. The reduction in coagulant demand following MIEX pretreatment observed in jar tests has been confirmed in pilot plant tests and full-scale installations [90]. MIEX pretreatment results in reductions in coagulant costs and reduces the amount of residuals to dispose of. Chlorination of the combined MIEX/coagulation samples shows reduction in chlorine demand and lower formation of THMs and HAAs relative to coagulated water [21, 29, 89].
Researchers have also shown that the floc formed after MIEX pretreatment is larger and stronger than the floc formed in corresponding raw water [91]. MIEX pretreatment followed by coagulation has also been used to remove multiple contaminants such as DOC and bromide [41], although the mechanism of bromide removal by coagulation is not well explained. Others have re-evaluated the sequence of MIEX resin and coagulation with the impact on other downstream processes in mind. For example, coagulation followed by MIEX treatment was shown to be more effective than MIEX alone in terms of reducing membrane fouling [92]. As a novel approach to coagulation, the combination of manganate oxidation, ferrous sulfate, and MIEX resin resulted in $92 \%$ DOC removal [93], which corresponded to a lower Fe dose than typically used for ferric coagulation. Coagulation followed by MIEX treatment (i.e., coagulation/MIEX) has been used to remove $62 \pm 7 \%$ DOC by coagulation and $32 \pm 16 \%$ bromide, $58 \pm 21 \%$ iodide, and $5 \pm 5 \%$ DOC by MIEX resin [67••]. This process sequence, however, does not take advantage of the benefits of MIEX treatment prior to coagulation as described above. In addition, coagulation/MIEX achieved lower overall DOC removal than coagulation/PAC, i.e., $66 \pm$ 12 vs. $70 \pm 10 \%[67 \bullet \bullet$, which is another indication that the sequence of coagulation followed by MIEX is not ideal.

\section{Membrane Technology}

There has been considerable interest in the potential for MIEX pretreatment to reduce fouling of MF, UF, NF, and RO membranes. MIEX pretreatment for removal of DOC has shown minor or negligible reductions in MF and UF membrane fouling [92, 94, 95]. However, MIEX/coagulation has shown greater reductions in MF and UF membrane fouling because of the complementary removal of dissolved (low molecular weight) and colloidal (high molecular weight) fractions of organic matter $[92,94,96]$. However, the effect of combined MIEX/coagulation on subsequent membrane fouling can depend on the coagulant type, where Choi et al. showed that polyaluminum chloride created larger floc and resulted in less MF flux decline than polyaluminum silicate [97]. With respect to secondary wastewater effluent, MIEX/alum coagulation showed a reduction in MF and UF membrane fouling relative to untreated and MIEX-treated secondary effluent [98 ${ }^{\circ}$, which is consistent with the previous results for drinking water sources.

MIEX pretreatment to reduce fouling of NF and RO membranes has also shown mixed results. MIEX treatment before NF membrane reduced the flux decline relative to raw water [99], while MIEX treatment before RO membrane showed no change in flux relative to the control condition [78]. A clear advantage of MIEX pretreatment is the high removal of DOC which contributes to an overall high contaminant rejection by combined MIEX/membrane systems [99]. 


\section{Activated Carbon}

MIEX has been evaluated as a pretreatment to GAC and PAC with the intent that MIEX resin would remove large extent of DOC and thereby increase the adsorption capacity of activated carbon. For example, PAC following MIEX treatment removed more pesticides than PAC alone due to pre-removal of DOC by MIEX resin [100]. MIEX resin has been investigated as a pretreatment to GAC for removal of methylisoborneol (MIB) and geosmin but the results were inconclusive as to the benefit of MIEX pretreatment relative to conventional pretreatment [101]. Investigation of the sequence of MIEX and BAC, i.e., MIEX/BAC versus BAC/ MIEX, showed that BAC/MIEX was the better process for DOC removal from secondary wastewater effluent because BAC increased the fraction of DOC that could be removed by MIEX resin [102]. In a follow-up research, however, $\mathrm{MIEX/BAC}$ showed a greater reduction in membrane fouling than BAC/MIEX, MIEX, or BAC for secondary wastewater effluent due to changes in DOM properties, such as removing low molecular weight compounds, which was favorable in terms of reduced membrane fouling [103].

\section{Ozone}

MIEX resin has been investigated as a pretreatment to ozonation as a means to increase the dissolved ozone concentration. For example, Johnson and Singer showed that at a given ozone dose the dissolved ozone concentration increased and the bromate formation decreased as the MIEX resin dose increased, which was due to the co-removal of DOC and bromide [32]. Pilot plant tests have also shown that MIEX pretreatment increases the dissolved ozone concentration which in turn increases the effectiveness of ozone disinfection [104]. The combination of MIEX pretreatment and ozone disinfection before final chlorination resulted in the lowest THM formation among alum coagulation, ozonation, and combined alum coagulation/ozonation [36].

\section{Lime Softening}

MIEX treatment prior to lime softening was shown to reduce the lime dose and increase hardness removal [34]. This result was because the substantial reduction in DOC by MIEX resin decreased the inhibition of calcium carbonate formation.

\section{Combined Ion Exchange}

As an alternative to using MIEX as a pre- or post-treatment process, Apell and Boyer proposed using magnetically enhanced anion exchange and cation exchange resins in the same reactor $[35,105]$, hereafter referred to as combined ion exchange. The purpose of the new process was to remove
DOC and hardness in the same reactor instead of using multiple processes such as MIEX followed by lime softening. Jar tests showed that anionic and cationic MIEX resins could be mixed together and achieve $70 \%$ DOC removal and $55 \%$ hardness removal [35]. The combined ion exchange process was further evaluated using MIEX resin for DOC removal and conventional cation exchange resin for hardness removal because the conventional cation exchange resin had a higher capacity than the magnetic cation exchange resin. For example, Comstock and Boyer showed that combined ion exchange could achieve $76 \%$ DOC removal and $97 \%$ hardness removal from groundwater [106]. MIEX, cation exchange, and combined ion exchange were investigated as pretreatment for RO membranes for groundwater high in DOC, hardness, and salinity. All three processes showed improvements in flux relative to untreated water [107].

\section{Case Study}

The Mt. Pleasant Water Treatment Plant (WTP) in South Australia presents a unique opportunity to study the MIEX process alone and combined with other processes. The Mt. Pleasant WTP treats water from the River Murray. Full-scale processes include MIEX followed by conventional treatment (coagulation, flocculation, and filtration) and MIEX followed by submerged MF membranes. Pilot-scale units for conventional treatment, membranes, and GAC have also been tested. For example, pilot plant tests of conventional treatment were compared with full-scale MIEX as pretreatment to GAC filters for removal of MIB and geosmin [101]. The impact of MIEX pretreatment on MF fouling [95] and bacteria removal [108] has also been investigated. A comprehensive 2-year study at the Mt. Pleasant WTP showed greater DOC removal by $\mathrm{MIEX} /$ coagulation and MIEX/MF than coagulation alone or MF alone [9]. In addition, water following MIEX treatment had lower SUVA254 and removal of wider range of apparent molecular weight fractions of DOM than other processes [9]. Statistical analysis of the various treatment trains at the Mt. Pleasant WTP considering DOC, UVA254, and molecular weight chromatograms showed the MIEX alone or MIEX combined with coagulation or MF achieved the greatest reductions in DOC and UVA254 and removal of a wider range of molecular weight fractions of DOM [109•]. MIEX/coagulation was able to achieve high and consistent level of DOC removal and UVA254 reduction during a 2year period of extreme weather that included drought and two major flood events [11••], thus illustrating the robustness of the MIEX process. Hence, the quantifiable improvements of using MIEX in place of coagulation alone or MF alone would be production of finished water of consistent quality despite changes in raw water quality. In addition, there would not need to be changes in operation of the MIEX process, whereas the coagulation process would require changes in 
coagulant dose with changing raw water quality. In terms of economics, MIEX or MIEX/coagulation would eliminate or substantially reduce the amount of coagulant needed. This would reduce water treatment operating costs in terms of coagulant and sludge disposal. In turn, there would be new operating costs for the MIEX process including periodic resin replacement and regeneration chemicals. A life cycle cost analysis would be needed to quantify the full economic costs and benefits of MIEX treatment.

\section{Impact on Water Distribution Systems}

Biofilm growth in water distribution systems is of high concern due to deterioration in the quality of finished drinking water. The impact of MIEX treatment on bacterial regrowth potential has shown mixed results. In some case, there was no difference in the bacterial regrowth potential following MIEX treatment compared with other processes like coagulation [29, 110]. However, other studies have shown MIEX treatment contributes to greater removal of bacteria [108], which could reduce the potential for bacterial regrowth.

MIEX treatment of drinking water, and anion exchange in general, has the potential to increase lead corrosion due to the co-removal of sulfate with DOC and the stoichiometric release of chloride. Specifically, removal of sulfate and release of chloride increases the chloride-to-sulfate mass ratio (CSMR), which has been shown to be predictive of lead corrosion [111]. Data from jar tests, pilot plant tests, and full-scale installations were analyzed for the impact of MIEX treatment on the CSMR. In general, MIEX treatment resulted in the largest increase in the CSMR among other treatment processes and incomplete rinsing of the resin could further increase the CSMR [28, 112]. At constant CSMR, high-chloride water showed greater lead release than low-chloride water [112], which supports the concern that anion exchange treatment can increase lead release in finished drinking water.

\section{Needs for Future Research}

Two aspects of MIEX treatment that would benefit from future research are testing procedures and system-level evaluations. Standard jar tests are the most widely used approach to evaluate the removal performance of MIEX resin. However, the typical jar test procedure (e.g., 5-10 mL/L MIEX resin, 15-30 min mixing time, and no regeneration) is the least representative of the continuous flow, completely mixed MIEX process. Although pilot plant tests and full-scale installations provide the most realistic data, it is often not feasible in terms of time or funding to do a pilot plant test or study a full-scale MIEX plant. As a result, the multiple-loading jar test procedure was developed as a more realistic representation of the full-scale MIEX process and more feasible to implement. Conceptually, the multiple-loading jar test procedure would appear to mimic the full-scale MIEX process; however, this has not been confirmed through experimentation. Comstock and Boyer provide data comparing the standard jar test procedure with the multiple-loading procedure [106]. The same effective resin dose was used in both procedures; however, MIEX resin showed higher removal of DOC, UVA254, and sulfate in the multiple-loading procedure than the standard jar test [106]. The reason for this discrepancy is likely due to the choice of mixing times. The standard jar test procedure should use a mixing time that is representative of the solid residence time of the MIEX process (e.g., 100-1000 min), whereas the multiple-loading procedure should use a mixing time that is representative of the hydraulic residence time of the MIEX process (e.g., 5-30 $\mathrm{min}$ ) [17, 47]. Once the corresponding conditions for the standard jar test procedure and multipleloading jar test procedure have been identified, then the next logical step is to confirm that the multiple-loading procedure agrees with the full-scale process. This can be accomplished by obtaining samples from MIEX pilot plants and full-scale installations and conducting parallel experiments with the raw water following the multiple-loading procedure as the same process operating conditions. The confirmation of laboratory procedures that give the same performance as the full-scale process will ensure that experimental results have real world relevance.

System-level evaluations of MIEX treatment are needed to better understand the linkages among natural and anthropogenic drivers, raw water quality, contaminant removal, regeneration efficiency, waste disposal, integration with other physical-chemical process, impacts on distribution, and finished water quality. For example, there is comprehensive research on MIEX treatment that spans changes in source water quality due to extreme events, integration of MIEX treatment with other physical-chemical processes, impacts on biofilm communities in water distribution systems, and finished water quality $[9,11 \bullet, 110]$. Others have conducted research on MIEX treatment that spans regeneration efficiency, waste disposal, integration with other physical-chemical process, impacts on corrosion in water distribution systems and household plumbing, and finished water quality [28, 112, 113]. Additional research on the depth and breadth of MIEX treatment illustrated here is needed to provide holistic solutions to water quality and treatment challenges.

\section{Conclusions}

MIEX resin has been demonstrated in numerous studies to be an effective process for removal of DOC and UVA254 from drinking water sources and wastewater effluent. In general, realistic doses of MIEX resin can achieve greater removal of 
DOC and UVA254 than alum or ferric coagulation. In addition, the type of DOM removed by MIEX resin often covers a wider range of hydrophilic, transphilic, and hydrophobic fractions and molecular weight fractions than coagulation or activated carbon adsorption. As a result, MIEX treatment results in substantial reductions in the formation of THMs and HAAs upon chlorination. The integration of MIEX treatment followed by coagulation shows multiple benefits including very high DOC removal, and reductions in coagulant dose, membrane fouling, and DBP formation. MIEX resin is a less effective technology for removal of bromide and other inorganic anions where more selective ion exchange resins are available.

Acknowledgments This publication was made possible by USEPA grant R835334. Its contents are solely the responsibility of the grantee and do not necessarily represent the official views of the USEPA. Further, USEPA does not endorse the purchase of any commercial products or services mentioned in the publication.

Conflict of Interest The author declares no conflict of interest.

\section{References}

Papers of particular interest, published recently, have been highlighted as:

- Of importance

•- Of major importance

1. Ritson JP, Graham NJD, Templeton MR, Clark JM, Gough R, Freeman $\mathrm{C}$. The impact of climate change on the treatability of dissolved organic matter (DOM) in upland water supplies: a UK perspective. Sci Total Environ. 2014;473-474(0):714-30.

2. Delpla I, Jung AV, Baures E, Clement M, Thomas O. Impacts of climate change on surface water quality in relation to drinking water production. Environ Int. 2009;35(8):1225-33.

3. Matilainen A, Vepsäläinen M, Sillanpää M. Natural organic matter removal by coagulation during drinking water treatment: a review. Adv Colloid Interf Sci. 2010;159(2):189-97.

4. Metsämuuronen S, Sillanpää M, Bhatnagar A, Mänttäri M. Natural organic matter removal from drinking water by membrane technology. Sep Purif Rev. 2012;43(1):1-61.

5. Matilainen A, Sillanpää M. Removal of natural organic matter from drinking water by advanced oxidation processes. Chemosphere. 2010;80(4):351-65.

6. Singer PC, Bilyk K. Enhanced coagulation using a magnetic ion exchange resin. Water Res. 2002;36:4009-22.

7. Allpike BP, Heitz A, Joll CA, Kagi RI, Abbt-Braun G, Frimmel $\mathrm{FH}$, et al. Size exclusion chromatography to characterize doc removal in drinking water treatment. Environ Sci Technol. 2005;39(7):2334-42.

8. Mergen MRD, Jefferson B, Parsons SA, Jarvis P. Magnetic ionexchange resin treatment: impact of water type and resin use. Water Res. 2008;42:1977-88.

9. Drikas M, Dixon M, Morran J. Long term case study of MIEX pre-treatment in drinking water; understanding nom removal. Water Res. 2011;45(4):1539-48.

10. Gan XJ, Kim D, Karanfil T. MIEX (r) treatment of an effluentimpacted stream. J Am Water Works Assoc. 2013;105(4):53-4.
11.• Braun K, Fabris R, Morran J, Ho L, Drikas M. Drought to flood: a comparative assessment of four parallel surface water treatments during the 2010-2012 inflows to the Murray-Darling Basin, South Australia. Sci Total Environ. 2014;488-489(0):36-45. Comprehensive assessment of changing water quality on robustness of MIEX treatment alone and in combination with other physical-chemical processes.

12. Graf KC, Cornwell DA, Boyer TH. Removal of dissolved organic carbon from surface water by anion exchange and adsorption: bench-scale testing to simulate a two-stage countercurrent process. Sep Purif Technol. 2014;122:523-32. This article compares DOC removal by MIEX resin with six other commercially available anion exchange resins that are marketed for organics removal.

13.• Nguyen HV, Bursill DB, Morran JY, Drikas M, Pearce VL. inventors. Orica Australia Pty Ltd, assignee. Water treatment process. United States patent US 6,669,849 B1. 2003 Dec 30. Patent for MIEX process

14.• Ballard MJ, Eldridge RJ, Bates JS, inventors. ICI Australi Operations Proprietary Limited, Industrial Research Organisation, assignee. Polymer beads and method for preparation thereof. United States patent US 6,171,489 B1. 2001 Jan 9. Patent for MIEX resin.

15. Slunjski M, Nguyen H, Ballard M, Eldridge R, Morran J, Drikas $\mathrm{M}$, et al. MIEX - good research commercialised. Water. 2002;29(2):42-7.

16. Jha AK, Bose A, Downey JP. Removal of $\mathrm{As}(\mathrm{V})$ and $\mathrm{Cr}(\mathrm{Vi})$ ions from aqueous solution using a continuous, hybrid field-gradient magnetic separation device. Sep Sci Technol. 2006;41(15):3297312.

17. Boyer TH, Miller CT, Singer PC. Modeling the removal of dissolved organic carbon by ion exchange in a completely mixed flow reactor. Water Res. 2008;42(8-9):1897-906. First mathematical model describing the MIEX process with focus on age distribution of resin.

18. Walker KM, Boyer TH. Long-term performance of bicarbonateform anion exchange: removal of dissolved organic matter and bromide from the St. Johns River, FL, USA. Water Res. 2011;45(9):2875-86.

19. Dronskowski R. The little maghemite story: a classic functional material. Adv Funct Mater. 2001;11(1):27-9.

20. Indarawis $\mathrm{K}$, Boyer TH. Alkaline earth metal cation exchange: effect of mobile counterion and dissolved organic matter. Environ Sci Technol. 2012;46(8):4591-8.

21. Boyer TH, Singer PC. A pilot-scale evaluation of magnetic ion exchange treatment for removal of natural organic material and inorganic anions. Water Res. 2006;40(15):2865-76.

22. Warton B, Heitz A, Zappia LR, Franzmann PD, Masters D, Joll CA, et al. Magnetic ion exchange drinking water treatment in a large-scale facility. J Am Water Works Assoc. 2007;99(1):89-101.

23. Kitis M, Harman BI, Yigit NO, Beyhan M, Nguyen H, Adams B. The removal of natural organic matter from selected Turkish source waters using magnetic ion exchange resin (MIEX (r)). React Funct Polym. 2007;67(12):1495-504.

24. Kabsch-Korbutowicz M, Majewska-Nowak K, Winnicki T. Water treatment using MIEX (r) doc/ultrafiltration process. Desalination. 2008;221(1-3):338-44.

25. Phetrak A, Lohwacharin J, Sakai H, Murakami M, Oguma K, Takizawa S. Simultaneous removal of dissolved organic matter and bromide from drinking water source by anion exchange resins for controlling disinfection by-products. J Environ Sci. 2014;26(6):1294-300.

26. Rokicki CA, Boyer TH. Bicarbonate-form anion exchange: affinity, regeneration, and stoichiometry. Water Res. 2011;45(3):132937. 
27. Zhang R, Vigneswaran S, Ngo H, Nguyen H. Fluidized bed magnetic ion exchange (MIEX (r)) as pre-treatment process for a submerged membrane reactor in wastewater treatment and reuse. Desalination. 2008;227(1-3):85-93.

28. Ishii SKL, Boyer TH. Evaluating the secondary effects of magnetic ion exchange: focus on corrosion potential in the distribution system. Desalination. 2011;274(1-3):31-8.

29. Drikas M, Chow CWK, Cook D. The impact of recalcitrant organic character on disinfection stability, trihalomethane formation and bacterial regrowth: an evaluation of magnetic ion exchange resin (MIEX (r)) and alum coagulation. J Water Supply Res Technol AQUA. 2003;52(7):475-87.

30. Karpinska A, Boaventura RR, Vilar VP, Bilyk A, Molczan M. Applicability of MIEX ${ }^{\circledR}$ doc process for organics removal from NOM laden water. Environ Sci Pollut Res. 2013;20(6):3890-9.

31. Boyer TH, Singer PC. Bench-scale testing of a magnetic ion exchange resin for removal of disinfection by-product precursors. Water Res. 2005;39(7):1265-76.

32. Johnson CJ, Singer PC. Impact of a magnetic ion exchange resin on ozone demand and bromate formation during drinking water treatment. Water Res. 2004;38(17):3738-50.

33. Humbert H, Gallard H, Suty H, Croue JP. Performance of selected anion exchange resins for the treatment of a high DOC content surface water. Water Res. 2005;39(9):1699-708.

34. Hsu S, Singer PC. Application of anion exchange to control NOM interference on lime softening. J Am Water Works Assoc. 2009;101(6):85-94.

35. Apell JN, Boyer TH. Combined ion exchange treatment for removal of dissolved organic matter and hardness. Water Res. 2010;44(8):2419 30.

36. Kingsbury RS, Singer PC. Effect of magnetic ion exchange and ozonation on disinfection by-product formation. Water Res. 2013;47(3):1060-72.

37. Crafton EA, Wu DY, Duirk SE. Comparison of anion exchange resins and aluminum-based coagulants for natural organic matter (NOM) removal and disinfection by-product (DBP) formation. Water Sci Technol Water Supply. 2014;14(4):577-84.

38. Ates N, Kitis M, Yetis U. Formation of chlorination by-products in waters with low SUVA-correlations with SUVA and differential UV spectroscopy. Water Res. 2007;41(18):4139-48.

39. Fearing DA, Banks J, Guyetand S, Eroles CM, Jefferson B, Wilson D, et al. Combination of ferric and MIEX (r) for the treatment of a humic rich water. Water Res. 2004;38(10):2551-8.

40. Comstock SEH, Boyer TH, Graf KC. Treatment of nanofiltration and reverse osmosis concentrates: comparison of precipitative softening, coagulation, and anion exchange. Water Res. 2011;45(16):4855-65.

41. Xu ZZ, Jiao RY, Liu HL, Wang DS, Chow CWK, Drikas M. Hybrid treatment process of using MIEX and high performance composite coagulant for DOM and bromide removal. J Environ Eng ASCE. 2013;139(1):79-85.

42. Hanigan D, Inniss E, Clevenger TE. MIEX (r) and PAC for removal of hydrophilic DBP precursors. J Am Water Works Assoc. 2013;105(3):41-2.

43. Ho L, Hainthaler M, Newcombe G. Using UV spectroscopy and molecular weight determinations to investigate the effect of various water treatment processes on nom removal: Australian case study. J Environ Eng ASCE. 2013;139(1):117-26. Comprehensive comparison of MIEX resin with other common processes in terms of DOM removal.

44. Shorrock K, Drage B. A pilot plant evaluation of the magnetic ion exchange (R) process for the removal of dissolved organic carbon at Draycote water treatment works. Water Environ J. 2006;20(2): 65-70.

45. Singer PC, Schneider M, Edwards-Brandt J, Budd GC. Magnetic ion exchange for the removal of disinfection by-product precursors: pilot plant findings. J Am Water Works Assoc. 2007;99(4):128-39.

46. Zappia LR, Warton B, Alessandrino M, Scott D, Wylie JT, Heitz A, et al. Pilot scale testing of biofilter post-treatment of MIEX (r) treated water. J Water Supply Res Technol AQUA. 2007;56(4): 217-32.

47. Boyer TH, Miller CT, Singer PC. Advances in modeling completely mixed flow reactors for ion exchange. J Environ Eng ASCE. 2010;136(10):1128-38.

48. Singer PC, Boyer T, Holmquist A, Morran J, Bourke M. Integrated analysis of NOM removal by magnetic ion exchange. J Am Water Works Assoc. 2009;101(1):65-73.

49. Bond T, Goslan EH, Parsons SA, Jefferson B. Disinfection byproduct formation of natural organic matter surrogates and treatment by coagulation, MIEX (r) and nanofiltration. Water Res. 2010;44(5):1645-53.

50. Anderson L, Walsh ME. Evaluation of temperature impacts on drinking water treatment efficacy of magnetic ion exchange and enhanced coagulation. J Water Supply Res Technol AQUA. 2012;61(7):403-12.

$51 . \bullet$ Gan XJ, Karanfil T, Bekaroglu SSK, Shan JH. The control of NDBP and C-DBP precursors with MIEX (r). Water Res. 2013;47(3):1344-52. This article is the first to evaluate multiple loading MIEX treatment on DBP formation and the first MIEX work to investigate N-DBPs

52. Zhang R, Vigneswaran S, Ngo HH, Nguyen H. Magnetic ion exchange (MIEX (r)) resin as a pre-treatment to a submerged membrane system in the treatment of biologically treated wastewater. Desalination. 2006;192(1-3):296-302.

53. Zhang R, Vigneswaran S, Ngo H, Nguyen H. A submerged membrane hybrid system coupled with magnetic ion exchange (MIEX (r)) and flocculation in wastewater treatment. Desalination. 2007;216(1-3):325-33.

54. Guo WS, Zhang R, Vigneswaran S, Ngo HH, Kandasamy J. Membranes coupled with physico chemical treatment in water reuse. Water Sci Technol. 2010;61(2):513-9.

55. Kim H-C, Dempsey BA. Removal of organic acids from EfOM using anion exchange resins and consequent reduction of fouling in UF and MF. J Membr Sci. 2010;364(1-2):325-30.

56. Myat DT, Mergen M, Zhao O, Stewart MB, Orbell JD, Gray S. Characterisation of organic matter in IX and PACl treated wastewater in relation to the fouling of a hydrophobic polypropylene membrane. Water Res. 2012;46(16):5151-64.

57. Nguyen TV, Zhang R, Vigneswaran S, Ngo HH, Kandasamy J, Mathes P. Removal of organic matter from effluents by magnetic ion exchange (MIEX $\left.{ }^{\circledR}\right)$. Desalination. 2011;276(1-3):96-102.

58. Zhang X, Li FZ, Zhao X. Application of a magnetic resin (MIEXA (r)) in wastewater reclamation for managed aquifer recharge. Water Air Soil Pollut. 2012;223(8):4687-94.

59. Zhang X, Zhao X, Gao YT, Zhang M. Removal of effluent dissolved organic matter of different molecular sizes by advanced treatments and soil infiltration. Water Environ Res. 2014;86(1): $81-6$.

60. Pidou M, Avery L, Stephenson T, Jeffrey P, Parsons SA, Liu S, et al. Chemical solutions for greywater recycling. Chemosphere. 2008;71(1):147-55.

61. Boyer TH, Graf KC, Comstock SEH, Townsend TG. Magnetic ion exchange treatment of stabilized landfill leachate. Chemosphere. 2011;83(9):1220-7.

62. Singh SK, Townsend TG, Boyer TH. Evaluation of coagulation (FeCl3) and anion exchange (MIEX) for stabilized landfill leachate treatment and high-pressure membrane pretreatment. Sep Purif Technol. 2012;96:98-106.

63. Palomino PA, Boyer TH. Magnetic ion exchange (MIEX) treatment of surface water, groundwater, and landfill leachate 
wastewater: effect on organic matter fluorescence. Sep Sci Technol. 2013;48(15):2277-86.

64. Dahlke T, Mathes PA, Adams B. Treatment of highly polluted paper and pulp effluent using combined treatment processes including a continuous ion exchange process. Proceedings Water Reuse and Recycling 2007;122-129.

65. Boyer TH, Singer PC. Stoichiometry of removal of natural organic matter by ion exchange. Environ Sci Technol. 2008;42:608-13.

66. Boyer TH, Singer PC, Aiken GR. Removal of dissolved organic matter by anion exchange: effect of dissolved organic matter properties. Environ Sci Technol. 2008;42(19):7431-7.

67.• Watson K, Farré MJ, Knight N. Enhanced coagulation with powdered activated carbon or MIEX ${ }^{\circledR}$ secondary treatment: a comparison of disinfection by-product formation and precursor removal. Water Res. 2015;68(0):454-66. This article is a comprehensive study on bromide removal by MIEX resin and the first to evaluate iodide removal by MIEX resin.

68. Ding L, Deng H, Wu C, Han X. Affecting factors, equilibrium, kinetics and thermodynamics of bromide removal from aqueous solutions by MIEX resin. Chem Eng J. 2012;181-182:360-70.

69. Hsu S, Singer PC. Removal of bromide and natural organic matter by anion exchange. Water Res. 2010;44:2133-40.

70. Boyer TH, Persaud A, Banerjee P, Palomino P. Comparison of low-cost and engineered materials for phosphorus removal from organic-rich surface water. Water Res. 2011;45:4803-14.

71. Ding L, Wu C, Deng H, Zhang X. Adsorptive characteristics of phosphate from aqueous solutions by MIEX resin. J Colloid Interface Sci. 2012;376(1):224-32.

72. Tang YL, Liang S, Guo HC, You HR, Gao NY, Yu SL. Adsorptive characteristics of perchlorate from aqueous solutions by MIEX resin. Colloid Surf A Physicochem Eng Asp. 2013;417:26-31.

73. Zhu Y, Gao N, Wang Q, Wei X. Adsorption of perchlorate from aqueous solutions by anion exchange resins: effects of resin properties and solution chemistry. Colloids Surf A Physicochem Eng Asp. 2015;468:114-21.

74. Ding L, Lu X, Deng HP, Zhang XX. Adsorptive removal of 2,4dichlorophenoxyacetic acid (2,4-d) from aqueous solutions using MIEX resin. Ind Eng Chem Res. 2012;51(34):11226-35.

75. Liu Z, Yan X, Drikas M, Zhou D, Wang D, Yang M, et al. Removal of bentazone from micro-polluted water using MIEX resin: kinetics, equilibrium, and mechanism. J Environ Sci. 2011;23(3):381-7.

76. Zhang X, Lu X, Li S, Zhong M, Shi X, Luo G, et al. Investigation of 2,4-dichlorophenoxyacetic acid adsorption onto MIEX resin: optimization using response surface methodology. J Taiwan Inst Chem Eng. 2014;45(4):1835-41.

77. Neale PA, Mastrup M, Borgmann T, Schafer AI. Sorption of micropollutant estrone to a water treatment ion exchange resin. J Environ Monit. 2010;12(1):311-7.

78. Huang H, Cho H, Schwab K, Jacangelo JG. Effects of feedwater pretreatment on the removal of organic microconstituents by a low fouling reverse osmosis membrane. Desalination. 2011;281:44654.

79. Tang Y, Li S, Zhang Y, Yu S, Martikka M. Sorption of tetrabromobisphenol A from solution onto MIEX resin: batch and column test. J Taiwan Inst Chem Eng. 2014;45(5):2411-7.

80. Fasfous II, Radwan ES, Dawoud JN. Kinetics, equilibrium and thermodynamics of the sorption of tetrabromobisphenol a on multiwalled carbon nanotubes. Appl Surf Sci. 2010;256(23): 7246-52.

81. Ates N, Incetan FB. Competition impact of sulfate on nom removal by anion-exchange resins in high-sulfate and low-SUVA waters. Ind Eng Chem Res. 2013;52(39):14261-9.

82. Subramonian S, Clifford D. Mono-valent divalent selectivity and the charge separation concept. React Polym. 1988;9(2):195-209.
83. Philippova O, Barabanova A, Molchanov V, Khokhlov A. Magnetic polymer beads: recent trends and developments in synthetic design and applications. Eur Polym J. 2011;47(4):542-59.

84. Shuang C, Li P, Li A, Zhou Q, Zhang M, Zhou Y. Quaternized magnetic microspheres for the efficient removal of reactive dyes. Water Res. 2012;46(14):4417-26.

85. Wang J, Li H, Li A, Shuang C, Zhou Q. Dissolved organic matter removal by magnetic anion exchange resin and released ion elimination by electrolysis. Chem Eng J. 2014;253:237-42.

86. Zhou Y, Shuang CD, Zhou Q, Zhang MC, Li PH, Li AM. Preparation and application of a novel magnetic anion exchange resin for selective nitrate removal. Chin Chem Lett. 2012;23(7): 813-6.

87. Chen W, Liu Y, Liu C. Preparation and use of magnetic poly(glycidyl methacrylate) resin in drinking water treatment. J Appl Polym Sci. 2013;130(1):106-12.

88. Jarvis P, Mergen M, Banks J, Mcintosh B, Parsons SA, Jefferson B. Pilot scale comparison of enhanced coagulation with magnetic resin plus coagulation systems. Environ Sci Technol. 2008;42(4): 1276-82.

89. Sani B, Basile E, Rossi L, Lubello C. Effects of pre-treatment with magnetic ion exchange resins on coagulation/flocculation process. Water Sci Technol. 2008;57(1):57-64.

90. Morran JY, Drikas M, Cook D, Bursill DB. Comparison of MIEX treatment and coagulation on NOM character. Water Sci Technol Water Supply. 2004;4(4):129-37.

91. Jarvis P, Jefferson B, Dixon D, Parsons SA. Treatment options and their effect on NOM-coagulant floc structures. J Am Water Works Assoc. 2008;100(1):64-73.

92. Humbert H, Gallard H, Jacquemet V, Croue JP. Combination of coagulation and ion exchange for the reduction of UF fouling properties of a high DOC content surface water. Water Res. 2007;41(17):3803-11.

93. Ren ZY, Graham N. Treatment of humic acid in drinking water by combining potassium manganate $(\mathrm{Mn}(\mathrm{Vi}))$, ferrous sulfate, and magnetic ion exchange. Environ Eng Sci. 2015;32(3):175-8.

94. Fabris R, Lee EK, Chow CWK, Chen V, Drikas M. Pre-treatments to reduce fouling of low pressure micro-filtration (MF) membranes. J Membr Sci. 2007;289(1-2):231-40.

95. Dixon MB, Morran JY, Drikas M. Extending membrane longevity by using MIEX as a pre-treatment. J Water Supply Res Technol AQUA. 2010;59(2-3):92-9.

96. Huang H, Cho H-H, Jacangelo JG, Schwab KJ. Mechanisms of membrane fouling control by integrated magnetic ion exchange and coagulation. Environ Sci Technol. 2012;46(19):10711-7.

97. Choi YH, Kweon JH, Jeong YM, Kwon S, Kim HS. Effects of magnetic ion-exchange resin addition during coagulation on floc properties and membrane filtration. Water Environ Res. 2010;82(3):259-66.

98. Kim HC. High-rate MIEX filtration for simultaneous removal of phosphorus and membrane foulants from secondary effluent. Water Res. 2015;69:40-50. This article evaluates alternative reactor configurations for MIEX.

99. Kaewsuk J, Seo GT. Verification of nom removal in MIEX-Nf system for advanced water treatment. Sep Purif Technol. 2011;80(1):11-9.

100. Humbert H, Gallard H, Suty H, Croue JP. Natural organic matter (NOM) and pesticides removal using a combination of ion exchange resin and powdered activated carbon (PAC). Water Res. 2008;42(6-7):1635-43.

101. Drikas M, Dixon M, Morran J. Removal of MIB and geosmin using granular activated carbon with and without MIEX pre-treatment. Water Res. 2009;43(20):5151-9.

102. Aryal A, Sathasivan A. Importance of the order in enhancing EfOM removal by combination of BAC and MIEX (r). Water Sci Technol. 2011;64(11):2325-32. 
103. Aryal A, Sathasivan A, Heitz A, Zheng G, Nikraz H, Ginige MP. Combined BAC and MIEX pre-treatment of secondary wastewater effluent to reduce fouling of nanofiltration membranes. Water Res. 2015;70:214-23.

104. Wert EC, Edwards-Brandt JC, Singer PC, Budd GC. Evaluating magnetic ion exchange resin (MIEX)(r) pretreatment to increase ozone disinfection and reduce bromate formation. Ozone Sci Eng. 2005;27(5):371-9.

105. Apell JN, Boyer TH. Simultaneous removal of dissolved organic matter and hardness by combined ion exchange. AWWA Water Quality Technology Conference and Exposition 2009; Seattle, Washington, 15-18 November 2009:8 p.

106. Comstock SEH, Boyer TH. Combined magnetic ion exchange and cation exchange for removal of DOC and hardness. Chem Eng J. 2014;241:366-75.

107. Indarawis KA, Boyer TH. Evaluation of ion exchange pretreatment options to decrease fouling of a reverse osmosis membrane. Desalin Water Treat Sci Eng. 2014;52(25-27):4603-11.

108. Ho L, Braun K, Fabris R, Hoefel D, Morran J, Monis P, et al. Comparison of drinking water treatment process streams for optimal bacteriological water quality. Water Res. 2012;46(12): 3934-42.
109. Aslam Z, Dixon M, Chow CWK, Morran J, Drikas M, van Leeuwen JA. Chemometric approaches to data assessment for a long-term case study of MIEX pretreatment performance. Desalin Water Treat Sci Eng. 2013;51(16-18):3639-49. Comprehensive data analysis on impact of MIEX treatment on DOC, UVA254, and molecular weight distribution.

110. Shaw JLA, Monis P, Fabris R, Ho L, Braun K, Drikas M, et al. Assessing the impact of water treatment on bacterial biofilms in drinking water distribution systems using high-throughput DNA sequencing. Chemosphere. 2014;117:185-92.

111. Edwards M, Triantafyllidou S. Chloride-to-sulfate mass ratio and lead leaching to water. J Am Water Works Assoc. 2007;99(7):96109.

112. Willison H, Boyer TH. Secondary effects of anion exchange on chloride, sulfate, and lead release: systems approach to corrosion control. Water Res. 2012;46(7):2385-94.

113. Maul GA, Kim Y, Amini A, Zhang Q, Boyer TH. Efficiency and life cycle environmental impacts of ion-exchange regeneration using sodium, potassium, chloride, and bicarbonate salts. Chem Eng J. 2014;254:198-209. 